[Agr. Biol. Chem., Vol. 31, No. 12, p. 1505 1508, 1967]

\title{
A Note on Radiation Resistance of Micrococcus radiodurans
}

\author{
By Yoshishige Okazawa and Akira Matsuyama \\ Radiobiology Laboratory, The Institute of Physical and Chemical \\ Research, Honkomagome, Bunkyo-ku, Tokyo \\ Received June 10, 1967
}

\begin{abstract}
Micrococcus radiodurans which is extremely resistant to both ionizing ${ }^{11}$ and ultraviolet radiations $^{2 \prime}$ has been recently received appreciable attention from viewpoint of radiobiology in order to make clear the primary mechanism for radiation resistance. Many investigations have been performed in respect of the radiation resistance and the repair mechanism for radiation damage in this bacterium. $^{3 \sim 7)}$ Although many biological and biochemical data have been obtained through these studies, details of the primary mechanism for radiation resistance operating in $M$. radiodurans still remain unclear. It appears necessary to accumulate more informations on this problem, comparing with other vegetative bacteria. This paper is concerned with the determination of radiosensitivity of $M$. radiodurans and its mutant M1 under different irradiation condition and estimation of the direct hits by radiation in their DNA, as a preliminary study on the high radioresistance of this bacterium.
\end{abstract}

1) A. W. Anderson, H. C. Nordan, R. F. Cain, G. Parrish and D. E. Duggan, Food Tech., 10, 575 (1956).

2) D. E. Duggan, A. W. Anderson, P. R. Elliker and R. F. Cain, Food Res., 24, 376 (1959).

$3)$ B. E. B. Moseley and A. H. Schein, Nature, 203, 1298 (1964).

4) J. K. Setlow and D. E. Duggan, Biochim. Biophys. Acta, 87, 664 (1964).

5) B. E. B. Moseley and H. Laser, Nature, 206 , 373 (1965).

6) C. J. Dean, P. Feldschreiber and J. T. Lett, ibid., 209, 49 (1966).

7) A. H. Schein, Biochem. J., 101, 647 (1966).
The red-pigmented wild-type $M$. radiodurans $\mathrm{R}_{1}$ and its less-pigmented mutant $\mathrm{Ml}$ were used in this study. The wild-type strain $R_{1}$ was kindly provided by Dr. A. W. Anderson of Oregon State University, and the mutant M1 was isolated from survivors of the strain $R_{1}$ after high dose gamma irradiation in this laboratory. Log- and stationary-phase cultures at $30^{\circ} \mathrm{C}$ in $\mathrm{B}$-broth (meat extract, $1 \%$; peptone, $10 \%$; yeast extract, $0.5 \%$; glucose, $0.2 \%^{\circ}$; and $\mathrm{pH}$ 7.0) were used for the determination of the radiosensitivity. Cells from these cultures were hed twice, resuspended in $0.067 \mathrm{~m}$ phosphate buffer ( $\mathrm{pH} 7.0$ ) and subjected to irradition.

Irradiation was carried out with cobalt-60 gamma rays at the dose rates of approximately $1.4 \times 10^{5} \mathrm{rads} / \mathrm{hour}$ for irradiation at room temperature (below $20^{\circ} \mathrm{C}$ ) and $10^{5} \mathrm{rads} / \mathrm{hour}$ for irradiation at liquid-nitrogen temperature $\left(-196^{\circ} \mathrm{C}\right)$. The cell concentration was about $10^{7}$ cells $/ \mathrm{ml}$. During irradiation at room temperature, air or nitrogen was bubbled through the suspension.

After irradiation, dilutions were made in phosphate buffer and platings for viable counts were done on B-broth with agar added to $1.5 \%$. Viable counts of the unirradiated control samples remained unchanged after the period to finish the irradiation with the maximum dose in liquid and solid phases (11 hours at room temperature and 100 hours at liquidnitrogen temperature, respectively), although the vigorous bubbling somewhat increased the 
viable counts with the rate of several per cent of the initial value. For estimation of mutation frequeney, colonies of the morphological mutant M1 including those with the sector

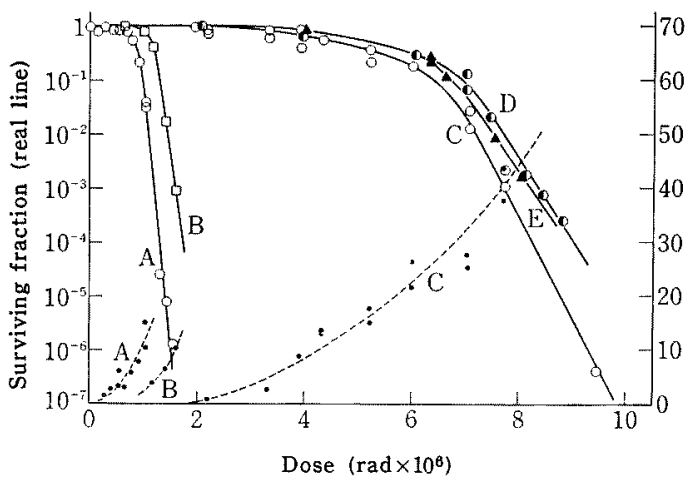

FIG. 1. Survival and Mutation Frequency (induction of $\mathrm{M} 1$ ) Curves of $M$. radiodurans (stationaryphase cells).

A: strain $R_{1}$, at room temperature, in air; $B$ : strain $R_{1}$, at room temperature, in nitrogen; $C \&$ $D$ : strain $R_{1}$, at liquid-nitrogen temperature, in air; E: strain $\mathrm{Ml}$, at liquid-nitrogen temperature, in air. of the mutant MI were counted. The total cell numbers were estimated by means of a Thoma's hemacytometer. The determination of DNA content was made on hot PGA-soluble extracts of bacterial cells by colorimetry according to the diphenylamine method of Burton $^{81}$ with highly polymerized calf thymus DNA as a standard.

Survival curves for the wild-type, redpigmented $M$. radiodurans $\mathrm{R}_{1}$ and its lesspigmented mutant $\mathrm{Ml}$ were determined at room and liquid-nitrogen temperatures. All of these curves were of sigmoidal type. Based on survival curve data which are partly illustrated in Fig. 1, the induction dose, ${ }^{9 \prime}$ the $D_{10}$ and the protecting factor afforded by freezing are listed in Table I. It should be noted that in the $\log$ and stationary phases the lesspigmented mutant $\mathrm{Ml}$ is not sensitive than the red-pigmented wild-type. This fact suggests that the system for pigmentation may not be involved in the primary mechanism of radiation resistance. As can be seen in Fig. 1, the very high radiation resistance was

TABLE I. RAdiosesitivities of THE Two StRains of $M$. radiodurans, STRAIN $R_{1}$ (red-pigmented wild-type) AND STRAIN Ml (less-pigmented mutant), UNDER DIFFERENT CONDITIONS OF IRRADIATION

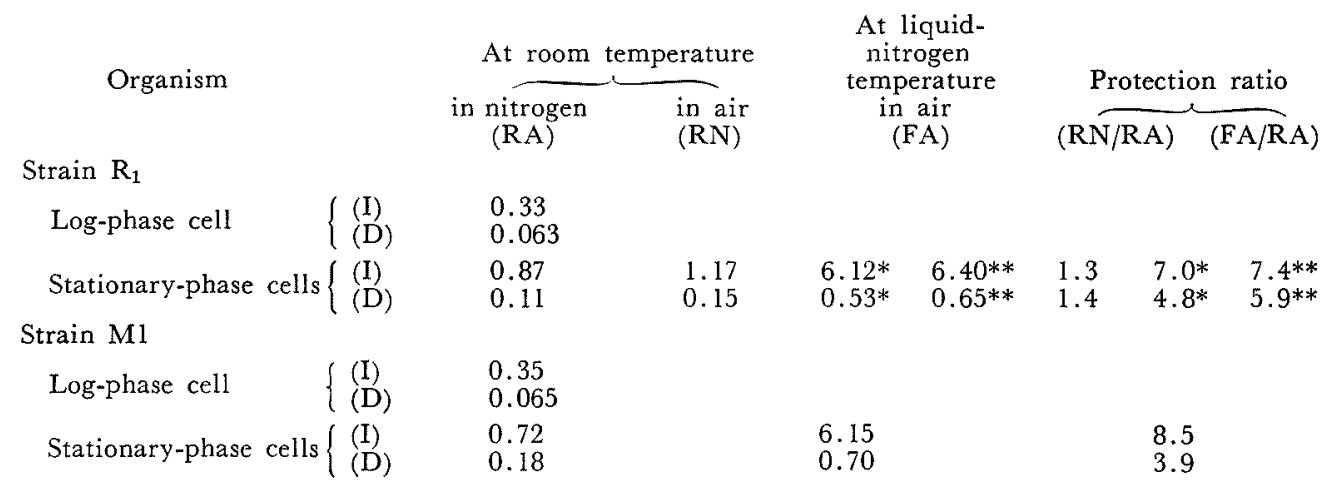

(I) Induction dose; (D) $\mathrm{D}_{10}$ value. Those parameters are represented in Mrads. Symbols * and $* *$ indicate the same run in the replicated experiments.

8) K. Burton, Biochem. J., 62, 315 (1956).

9) M. Ingram, In discussion after the presentation of the paper by W. P. Segner and C. F. Schmidt, Proc. Intern. Symp. on Food Irradiation (IAEA/FAO), Karlsruhe, p. 287 (1966). 
Table II. DNA Content of Microbial Cells and Direct Hits in DNA BY PRIMARY IONIZATION

Organism
$M$. radiodurans $\mathrm{R}_{1}$
Stationary-phase
Log-phase
M. radiodurans $\mathrm{Ml}$
Stationary-phase
Log-phase
$\mathrm{S}-13$ phage
$\mathrm{T}-1$ phage
E. coli ${ }^{\mathrm{b})}$
E. coli $\mathrm{B}_{\mathrm{s}-1}^{\mathrm{d})}$
E. coli $\mathrm{B} / \mathrm{r}^{\mathrm{d})}$

DNA conten
$(\mathrm{gm} /$ monococcal

$4.9 \times 10^{-14}$
$3.5 \times 10^{-14}$

$5.9 \times 10^{-14}$
$4.6 \times 10^{-14}$
$4 \times 10^{-18}$
$8 \times 10^{-17}$
$6 \times 10^{-15}$
$1.20 \times 10^{-14}$
$1.54 \times 10^{-14}$

$$
\begin{aligned}
& \text { Dose (rads) } \\
& \begin{array}{r}
\left.3,000,000^{\nexists}\right) \\
300,000^{\text {r }}
\end{array} \\
& 3,000,000 \cong \\
& 200,000 \text { f) } \\
& \left.250,000^{\circ}\right) \\
& 90,000 \approx \\
& \begin{array}{r}
2,000 \sim 5,000 \text { (1) } \\
2,500 \approx)
\end{array} \\
& 6,100=
\end{aligned}
$$$$
\begin{aligned}
& \text { Direct hits in DNA } \\
& \text { (/cell) }
\end{aligned}
$$$$
1.2 \times 10^{5}
$$$$
1.2 \times 10^{4}
$$$$
5.6 \times 10^{3}
$$$$
1.4 \times 10^{5}
$$$$
7.4 \times 10^{3}
$$$$
0.9
$$$$
6.3
$$$$
10 \sim 25
$$$$
24
$$$$
75
$$
a) The quotient (the amount of DNA/ total number of cells)
b) Data from ref. 12, p. 258. Direct hits in DNA were calculated on the basis of $72 \mathrm{eV} /$ effective event in ref. 12 .
c) $\mathrm{D}_{37}$
d) Calculated from data in ref. 13, p. 176 and p. 178.
e and $f)$ The dose required for $90 \%$ survivors at liq. nitrogen temperature and at room temperature,

observed in frozen state. It would be noteworthy to mention that the induction dose of this bacterium, about 6 Mrads, in frozen state irradiation is larger than the sterilization dose in radapperitization, ${ }^{10)} 4.5 \mathrm{Mrads}$, which corresponds to the $12 \mathrm{D}$ value of Clostridium botulinum spore (type $A$ and type $B$ ). With stationary-phase cells of the strain $R_{1}$, radioprotecting factor afforded by freezing is 7.0 7.4 for the induction dose and 4.8 5.9 for the $D_{10}$. The factor for the $D_{10}$ is not unusual in comparison with those for other species of vegetative bacteria obtained in frozen state irradiation, ${ }^{111}$ although the factor for the induction dose of $M$. radiodurans is comparatively large. The condition of irradiation in nitrogen at room temperature gave considerably less protection than freezing, with the ratio (RN/ RA) of 1.3 and 1.4 for the induction dose and the $D_{10}$ value, respectively. These values are rather small in comparison with those of

10) H. E. Goresline et al., Nature, 204, 237 (1964).

11) A. Matsuyama, M. J. Thornley and M. Ingram, J. Appl. Bacteriol., 27, 110 (1964). radioprotecting factor afforded by anoxia in other bacteria of normal radiation sensitivity. Mutation frequency for the radiation induction of the morphological mutant M1 from the wild type is also indicated in Fig. 1. Attention should be paid to the high mutation frequency. This fact might be due to comparatively larger doses used here because of the extreme radioresistance of this bacterium in terms of viability. The shape of the sector resulting from induction of the mutant M1 suggests the equal growth rate of the strain $\mathrm{R}_{1}$ and $\mathrm{Ml}$. The mutant $\mathrm{Ml}$ appeared insensitive to the radiation induction of back mutation.

Since the DNA was regarded as a candidate for a principal target for radiation inactivation of bacterial cells, the number of direct hit in the DNA was estimate with $M$. radiodurans. The results are indicated in Table II. For comparison, data presented by other authors ${ }^{12,131}$

12) W. R. Guild, Radiation Res. Suppl., 3, 257 (1963).

13) G. E. Stapleton and W. D. Fisher, Radiation Res., 30, 173 (1967). 
are added to the same table. The DNA content in a monococcal cell was found slightly higher in the mutant Ml than in the wildtype. The amount of DNA per cell was only somewhat larger in $M$. radiodurans than in $E$. coli. On the other hand, $M$. radiodurans has been found far more radioresistant than $E$. coli.

If one could postulate that an average ion cluster contains about 2.3 primary ion pairs, ${ }^{121}$ the mean energy dissipated in one effective event is $78 \mathrm{eV}(=34 \mathrm{eV} \times 2.3)$. On this basis, the direct hits by effective primary ion clusters in DNA at a given dose, $D$, are calculated as follows: hits in DNA $=8 \times 10^{11} \times \mathrm{gm} \mathrm{DNA} \times D$ (rad). When stationary-phase cells of $M$. radiodurans $\mathrm{R}_{1}$ were irradiated with $0.3 \mathrm{Mrads}$ at room temperature and with $3 \mathrm{Mrads}$ at liquid-nitrogen temperature, survivors were about $90 \%$, as shown in Fig. 1. At the doses required for $90 \%$ survivors, hits in DNA per cell are calculated as the order of approximately $10^{3} \sim 10^{5}$ (Table II). These large numbers of direct hits in DNA, especially those obtained in the frozen state, raise difficulties for our understanding the radiation lethal mechanism from viewpoint of the classic target theory. In this experiment, cells of $M$. radiodurans were mostly in tetracoccus type and partly in diploccoccus type. The mean values of the monococcal single cell number in an unit as a diplo- or tetracoccus were ranged between 3.28 and 3.45. However, one can not fully interprete high radiation resistance of these cells showing a sigmoidal curve on the basis of such cell aggregation.

In respect of this problem, Guild has described three possible explanations for survivors with large numbers of damaged DNA molecules, (1) the presence of the unfunctional DNA, (2) uncertainty of the process from molecular mutational damage to physiological mutation, and (3) bypass or repairing system for the damaged DNA. ${ }^{12}$ Dean et al. recently pointed out importance of the repair of radiation damage to the DNA in $M$. radiodurans in terms of the survival of the cells. ${ }^{6)}$ This view would be an interpretation for the large number of direct hits in the DNA by radiation. However, it is unlikely that the repair in damaged DNA is an only mechanism for high radiation resistance, as suggested by the same authors. In the case of such a highly resistant bacterium, it appears necessary to study the significance of the radiation damage in cytoplasmic targets as well as in the DNA. Further investigations in this series are under way in this laboratory to elucidate the whole picture of the extremely high radiation resistance of this bacterium.

Acknowledgements. The authors thank Dr. A. W. Anderson of Oregon State University, U.S.A., for the strain. They are also grateful to Mr. A. Tawada and Mrs. U. Miyazawa for their excellent technical assistance. This work was supported by a research grant of the Ministry of Education, Japan. 